\title{
Los acuerdos mixtos para los trabajadores y funcionarios de las Entidades Locales
}

\author{
Remedios Roqueta Buj \\ Catedrática de Derecho de Trabajo y de la Seguridad Social \\ Universitat de les Illes Balears
}

Sumario: 1. LA VIABILIDAD DE LOS ACUERDOS LOCALES MIXTOS. 1.1. Los sujetos negociadores. 1.2. El procedimiento de negociación. 1.3. El contenido de la negociación. 1.4. La jurisdicción competente. 2. LA IMPUGNACIÓN DE LOS ACUERDOS LOCALES MIXTOS.

1. La Sentencia de 22 de octubre de 1993 (Ar. 7.544) de la Sala 3. del Tribunal Supremo se enfrenta con una de las cuestiones que plantea la pervivencia en el seno de la Administración Pública de dos sistemas de negociación —el laboral y el funcionarial-, a saber: la viabilidad del ejercicio conjunto del derecho de negociación colectiva de los trabajadores y funcionarios al servicio de la Administración Pública ${ }^{1}$. Se ocupa, pues, de un tema sobre cuya relevancia y actualidad no puede caber duda alguna, sobre todo si se toma nota de la escasez de pronunciamientos de los tribunales al respecto. Merece la pena, por todo ello, dedicar a esa sentencia un breve comentario, aunque sólo sea para poner de relieve los puntos suscitados a lo largo del proceso y las respuestas ofrecidas por el Tribunal Supremo.

2. Esta resolución judicial resuelve un recurso de apelación planteado por el Abogado del Estado, en la representación que le es propia y al

\footnotetext{
I Sobre la viabilidad del ejercicio conjunto del derecho de negociación colectiva de trabajadores y funcionarios ver $R$. RoQUETA BUJ, «Las relaciones entre los sistemas de negociación colectiva laboral y funcionarial en la Administración Pública», en AA.VV., XI Jornadas Universitarias Andaluzas de Derecho del Trabajo y Relaciones Laborales, Madrid, 1994, pp. 147 y ss.; y J. FernánDEZ Dominguez y S. Rodriguez Escanciano, La Negociación Colectiva de los Funcionarios Públicos, Barcelona, 1996, pp. 75 y ss.

Sobre el alcance de las reformas que el Anteproyecto de Ley Reguladora del Estatuto de la Función Pública (EBFP) proyectaba introducir en la materia que nos ocupa ver $\mathrm{R}$. CATALÁ PoLo, «El régimen jurídico de los empleados en los sistemas privados de gestión de los servicios públicos. Aproximación de regímenes en la Administración General del Estado», DA, n. ${ }^{\circ} 243,1995$, pp. 128-129; G. P. Rojas Rivero, «Notas sobre la negociación colectiva en el Anteproyecto Básico de la Función Pública», RDS, n. ${ }^{\circ}$ 1, 1998, pp. 233 y ss.; R. ROQUETA BUJ, «La negociación colectiva en el proyecto de estatuto básico de la función pública», $A L$, n. ${ }^{\circ} 33,1998$, pp. 613 y ss.; y I. MARÍN ALoNso, «Problemática de la negociación colectiva funcionarial en el anteproyecto de estatuto básico de la función públican, Estudios Financieros, Revista de Trabajo y Seguridad Social, n. ${ }^{\circ}$ 193, 1999, pp. 3 y ss.
} 
amparo de las facultades reconocidas a la Administración del Estado por el artículo 65 de la Ley 7/1985, de 2 de abril, Reguladora de las Bases de Régimen Local (LBRL) ${ }^{2}$, y por la representación procesal del Excmo. Ayuntamiento de Albacete contra la Sentencia de 11 de abril de 1990 de la Sala de lo Contencioso-Administrativo del Tribunal Superior de Justicia de Castilla-La Mancha, en la que se estimaba parcialmente el recurso interpuesto por el Abogado del Estado contra el Acuerdo del Pleno del Ayuntamiento de Albacete, de 22 de marzo de 1989, aprobatorio del convenio colectivo afectante a «los funcionarios y personal laboral fijo del Excmo. Ayuntamiento de Albacete» (art. 1), concertado en el seno de la Mesa de Negociación compuesta por representantes sindicales y de la Corporación, declarándolo nulo.

El debate contradictorio entre ambas representaciones se plantea acerca de la validez de determinadas cláusulas del citado convenio colectivo con respecto al personal funcionario, a saber: a) La reducción de jornada a los funcionarios con hijos menores de 10 años (art. 6); b) El incremento del período de vacaciones teniendo en cuenta los años de servicio del funcionario (art. 7); c) El establecimiento de «nueve días de vacaciones al año retribuidas» (art. 9); d) La elevación de la cuantía de las retribuciones por encima del porcentaje global del 4 por 100 fijado en el artículo 25 de la Ley 37/1988, de 29 de diciembre, de Presupuestos Generales del Estado; e) El reconocimiento del derecho a percibir las pagas extraordinarias durante el tiempo de cumplimiento del servicio militar o servicio civil sustitutorio (art. 30); f) La ruptura del concepto unitario del complemento de productividad, escindiéndolo en tres; g) La incentivación mediante el abono de cantidades a tanto alzado a quienes opten por la jubilación anticipada (art. 24).

Sin embargo, el Tribunal Supremo, consciente de que «la peculiaridad de un pacto aplicable globalmente a un colectivo que está sujeto a sendos ordenamientos sustantivos netamente diferenciados, sugiere la previa interrogación acerca de la normalidad jurídica de este fenómeno, a cuya contestación se halla también vinculada la conclusión sobre la validez de lo pactado" (f.j. 4) y, siendo que este extremo no había sido tomado en consideración por las partes como fundamento de sus respectivas pretensiones, abre un período de audiencia, de conformidad con el artículo 43.2 de la anterior Ley de la Jurisdicción Contencioso-Administrativa, de 27 de diciembre de 1956 (LJCA), a dichos efectos ${ }^{3}$. Transcurrido el plazo

2 Precepto que ha sido modificado por la Ley 11/1999, de 21 de abril.

${ }^{3}$ A este respecto, debe subrayarse que las potestades de los tribunales en el orden contencioso-administrativo para enjuiciar de oficio cuestiones no planteadas por las partes se extiende en general a 
concedido sin que por ninguna de las partes se hubiera formulado alegaciones acerca del extremo cuestionado en la audiencia, el Tribunal Supremo aborda su análisis y saca las pertinentes conclusiones en conexión con lo pedido por los intervinientes en el proceso.

3. Los dos aspectos centrales del tema planteado son, por tanto, los siguientes: $1^{\circ}$ ) la viabilidad de los Acuerdos Locales Mixtos, en los que se regula unitariamente las condiciones de trabajo del personal laboral y funcionarial; y $2 .^{\circ}$ ) la impugnación de los Acuerdos Locales Mixtos.

\section{LA VIABILIDAD DE LOS ACUERDOS LOCALES MIXTOS}

4. En resoluciones precedentes, en las que se discutía la validez de convenios unitarios para trabajadores y funcionarios de las Entidades Locales (EE.LL.) suscritos con anterioridad a la vigencia de la Ley 9/1987, de 12 de junio, de Órganos de Representación, Determinación de las Condiciones de Trabajo y Participación del Personal al servicio de las Administraciones Públicas (LORAP) ${ }^{4}$, el Tribunal Supremo, siguiendo la doctrina del Tribunal Constitucional, había declarado su nulidad en base al carácter estatutario de la relación funcionarial y la falta de regulación en este ámbito de la negociación colectiva ${ }^{5}$. En este sentido, el citado Tribunal señalaba que «en todo caso la inclusión en un mismo convenio colectivo de funcionarios (contenido entonces ilegal) y de empleados en régimen laboral (ámbito este último en el que la negociación colectiva sí era posible) vicia de por sí al convenio como un todo, pues, como dice la Sentencia del Tribunal Constitucional 57/1982, en doctrina que, dado el marco normativo vigente en la ocasión de autos, conserva su validez en el (f.j. 4), «de la legislación vigente no es posible racionalmente inducir un principio básico que no sea el del tratamiento no unitario por diferenciado entre funcionarios públicos y personal laboral al servicio de las Corporaciones Locales y que en la actualidad la negociación colectiva de las condiciones de trabajo del personal vinculado a cualquiera de las

cualquier motivo que pudiera fundar el recurso o la oposición. Cfr. J. González Pérez, Manual de Derecho Administrativo, Madrid, 1992, pp. 434 y ss.

${ }^{4}$ Disposición legal parcialmente modificada por la Ley 7/1990, de 19 de julio, sobre Negociación colectiva y Participación en la Determinación de las Condiciones de Trabajo de los empleados públicos, y por la Ley 18/1994, de 30 de junio, por la que se modifica la normativa de elecciones a órganos de representación del personal al servicio de las Administraciones Públicas.

${ }^{5}$ SSTS de 1 de marzo de 1983 (Ar. 1.357), 22 de octubre de 1986 (Ar. 8.048), 27 de enero de 1987 (Ar. 2.002); SSTS de 29 de junio y 30 de octubre de 1992 (Ar. 5.195 y 8.397), 18 y 22 de marzo de 1993 (Ar. 2.074 y 2.116 ), 6, 16 y 30 de junio, 1,12 y 18 de julio, 16 de septiembre y 2 de noviembre de 1994 (Ar. 5.108, 5.289, 5.203, 5.688, 5.714, 6.102, 7.021 y 8.764). 
Administraciones públicas sólo es posible legalmente cuando se trata de personal sometido al Derecho laboral, pero no, en cambio, en relación al personal vinculado al Derecho administrativo..», sin que sea posible escindir la unidad del Convenio, según la Sentencia de este Tribunal de $27-1-87 \gg 6$.

5. Esta posición del Tribunal Supremo tiene un fundamento sólido, pero no expresa una opinión definitiva. En sus resoluciones judiciales se afirma que los funcionarios públicos no tienen garantizado ni constitucional ni legalmente el derecho a la negociación colectiva. Siendo esto así, era inevitable que se rechazara el principio de equiparación de sistemas de negociación entre el personal laboral y funcionario dependiente de la Administración Pública.

6. Ahora bien, una vez se ha reconocido el derecho a la negociación colectiva de los funcionarios, se abre una perspectiva nueva ante el tema. Así lo reconoce el propio Tribunal Supremo en la Sentencia objeto de comentario al decir que: «en el supuesto que aquí se plantea el convenio combatido fue suscrito bajo la vigencia de la ley citada (Ley 9/1987), la cual sirve de cobertura dialéctica de los argumentos esgrimidos en el debate en defensa de las respectivas posiciones. En consecuencia, lo que debe ahora dilucidarse consiste en determinar si los respectivos ordenamientos de la negociación colectiva (el de las relaciones estatutarias de los funcionarios públicos y el de las relaciones laborales de los trabajadores) ofrecen entre sí el grado de permeabilidad suficiente para posibilitar una negociación y eventual regulación unitaria bajo forma contractual, $y$, para ello, deben ponerse en relación los componentes básicos de los respectivos sistemas» (f.j. 5).

7. Siguiendo el orden de los factores enumerados, el Tribunal Supremo subraya las siguientes diferencias de régimen jurídico entre los sistemas de negociación colectiva funcionarial y laboral 7: «a) la estructura

\footnotetext{
6 STS de 18 de marzo de 1993.

${ }^{7}$ En cuanto al régimen jurídico aplicable a la negociación colectiva funcionarial ver, por todos, $\mathrm{A}$. BLASCO ESTEVE, «La negociación colectiva de los funcionarios publicos», REDA, n. ${ }^{\circ} 52,1986, \mathrm{y}$ «La negociación colectiva de los funcionarios públicos en la Administración Local», en AA.VV., Tratado de Derecho Municipal (coord. Muñoz Machado), tomo II, Madrid, 1988; S. DEL REY GuANTER, Comentarios a la Ley de Órganos de Representación, Determinación de las Condiciones de Trabajo y Participación del Personal al servicio de las Administraciones Públicas, MAP, Madrid, 1988; P. Gómez CABALLero, Los derechos colectivos de los funcionarios, CES, Madrid, 1994; J. MAURI MAJOS, «Problemas de representación sindical y la negociación colectiva en la función pública. Convergencias y divergencias con el empleo privado", DA, n. 214-242, 1995; T. SALA Franco y R. RoQueta Buj, Los derechos sindicales de los funcionarios públicos, Valencia, 1995;
} 
orgánica representativa integrada en la Mesa de negociación a que se refiere el artículo 31.2 de la Ley $9 / 1987$, no es coincidente con la prevista en el artículo 87.1 de la Ley 8/1980 para la constitución de la Comisión Negociadora; b) el grado de autonomía de la negociación colectiva de los funcionarios, resultante de los artículos 32 y 35 de la Ley 9/1987, es manifiestamente más limitado que el reconocido a los trabajadores en el artículo 85 de la Ley $8 / 1980$; c) la situación de supremacía de una de las partes, reflejada en el artículo 35 de la Ley $9 / 1987$ —al requerir la validez y eficacia de los pactos y acuerdos negociados la aprobación expresa y formal del Pleno de la Entidad Local respectiva-, no tiene correlación en la letra de los artículos 82 y 90.2 de la Ley $8 / 1980$, aplicables inclusive cuando el empresario sea la entidad pública; d) la misma diferencia de régimen jurídico se observa - en el supuesto de fracaso de la negociación- entre lo establecido en el artículo 37.2 de la Ley 9/1987 y la regulación que deriva del Título II del RD-Ley 17/1977, de 4 de marzo, y la STC 11/1981, de 8 de abril; e) igualmente es notoria la diferencia en las reclamaciones jurisdiccionales relativas a esta materia, reservadas al orden contencioso-administrativo tratándose de funcionarios (arts. 9.4 y 24 LOPJ), en tanto es competencia del orden social cuando conciernen al personal laboral, sea pública o privada la unidad empleadora (arts. 9.5 y 25 LOPJ)» (f.j. 6).

\footnotetext{
R. RoQUETA BUJ, La negociación colectiva en la función pública, Valencia, 1996, «El contenido de la negociación colectiva en materia de clasificación de puestos de trabajo y de retribuciones de los funcionarios locales», Poder Judicial, n. ${ }^{\circ} 43-44,1996$, y «La negociación colectiva en la función pública local», Revista de Estudios de la Administración Local y Autonómica, n. ${ }^{\circ} 279$, 1999; J. J. Fernández Dominguez y S. Rodriguez Escanciano, La Negociación Colectiva de los Funcionarios Públicos, Barcelona, 1996; A. Palomar Olmeda, Derecho de la Función Pública, Régimen juridico de los funcionarios públicos, Madrid, 1996; R. MANzana Laguarda, Derechos y deberes de los funcionarios públicos, Valencia, 1996; S. DEl Rey GUANTER y M. Luque PARRA, «Criterios jurisprudenciales recientes sobre la negociación colectiva de los funcionarios públicos», $R L, \mathrm{n} .^{\circ} 4,1997$, pp. 12 y ss.; M. Rodríguez Piñero, «Ley y negociación colectiva en la función pública», $R L$, II/1997, pp. 9 y ss.; M. SÁNChez Morón, Derecho de la función pública, 1997, pp. 234 y ss.; y F. VALDÉs DAL-RE, «Los derechos de negociación colectiva y de huelga de los funcionarios públicos en el ordenamiento jurídico español: una aproximación», REDT, n. ${ }^{\circ} 86,1997, \mathrm{pp} .837$ y ss. Además, debe tenerse en cuenta la abundantísima bibliografia que se cita en R. ROQUETA BUs, La negociación colectiva..., cit.
}

En cuanto al régimen jurídico aplicable a la negociación colectiva laboral en el ámbito de las Administraciones Públicas ver, por todos, T. Sala Franco, Incidencia de la legislación laboral en el marco de la Función Pública, Madrid, 1989; R. RoQUETA BUJ, «El proceso de formación y remodelación de la estructura de la negociación colectiva laboral en el ámbito de la Administración del Estado", RTSS, n. ${ }^{\circ} 11$, 1993, y "Las relaciones entre...», cit.; J. M. LOPEZ GÓMEZ, El régimen jurídico del personal laboral de las Administraciones Públicas, Madrid, 1995; y M. LUQUE PARRA, «La capacidad de la Administración Pública para negociar convenios colectivos supraempresariales: una valoración de la problemática a propósito de la reforma del artículo 15.1 del TRLET», REDT, n. ${ }^{\circ} 90,1998$. 
8. Ahora bien, ¿estas diferencias tienen tanta trascendencia como para impedir la negociación conjunta de trabajadores y funcionarios? A juicio del Tribunal Supremo, sí. En este sentido, el citado Tribunal afirma que: «La trascendencia de las citadas contradicciones pone de manifiesto la inviabilidad de una articulación unitaria del pacto que abarque conjuntamente a los funcionarios y al personal laboral cuyo primer escollo, como hemos dicho, se manifiesta en la dualidad de instancias jurisdiccionales en concurrencia». Por ello, «procede $\{\ldots\}$ la declaración de nulidad de conformidad con los artículos 47.1.c) y 47.2 de la Ley de Procedimiento Administrativo, aunque, por razones de obligada congruencia con las pretensiones mantenidas en el proceso, esta declaración de nulidad debe limitarse estrictamente en cuanto a su alcance a las estipulaciones que el Abogado del Estado impugnó en el escrito de demanda y están especificadas en el FD $1 .^{\circ}$ de esta Sentencia y sin extenderse a los actos firmes y efectos agotados como consecuencia de la aplicación de las cláusulas anuladas» (f.j. 6) ${ }^{8}$.

9. Sin embargo, esta afirmación requiere una mayor reflexión, pues las diferencias que señala el Tribunal Supremo o no son tales diferencias o no tienen tanta trascendencia como para impedir la negociación conjunta de trabajadores y funcionarios. En relación con la posibilidad de sortear la concurrencia de sistemas de negociación en las EE.LL. a través de la negociación conjunta de personal laboral y funcionarial, debe distinguirse según el aspecto que se tome en consideración.

\subsection{Los sujetos negociadores}

10. Desde la perspectiva subjetiva, en principio, nada se puede objetar a que se produzca este tipo de combinación. Por lo que respecta a la representación de la Entidad local, porque los máximos responsables en materia de personal funcionario también lo son en relación con el personal laboral. Efectivamente, el Pleno de los Ayuntamientos y Diputaciones y los Alcaldes y Presidentes de las Diputaciones forman los dos vértices esenciales sobre los que se asienta el edificio orgánico del que se dota la parte «empresarial» para hacer frente a sus relaciones no sólo con los funcionarios públicos sino también con el personal laboral. A los Plenos les corresponde, entre otras competencias, aprobar la plantilla de personal y la relación de puestos de trabajo, fijar la cuantía de las retribuciones complementarias fijas y periódicas de los funcionarios [arts. 22.2.i) y

8 En el mismo sentido, R. Manzana Laguarda, Derechos y deberes..., cit., pp. 268-269. 
33.2.f) LBRL] y aprobar los presupuestos [arts. 22.2.e) y 33.2.c) LBRL]. Y los Alcaldes y Presidentes de las Diputaciones Provinciales aprueban la oferta de empleo público y las bases de las pruebas para la selección del personal y para los concursos de provisión de puestos de trabajo, distribuyen las retribuciones complementarias que no sean fijas y periódicas y desempeñan la jefatura superior de todo el personal de la Corporación [arts. 21.1.g) y h) y 34.1.g) y h) LBRL].

11. En cuanto a la representación de los empleados, tampoco se puede objetar a que se produzca este tipo de combinación. En la medida en que la Administración Local tiene personalidad jurídica única, habrá que darle, tal y como reconoce el Tribunal Supremo en la Sentencia que se comenta, el tratamiento de convenio de empresa ${ }^{9}$, por lo que, de acuerdo con las reglas de legitimación exigidas por el artículo $87.1 \mathrm{del}$ Real Decreto Legislativo 1/1995, de 24 de marzo, por el que se aprueba el Texto Refundido de la Ley del Estatuto de los Trabajadores (ET) y 8.2.b) de la Ley Orgánica 11/1985, de 2 de agosto, de Libertad Sindical (LOLIS), podrán negociar, del lado de los trabajadores, las secciones sindicales de los sindicatos más representativos y de los que tengan presencia en los órganos de representación unitaria. Ahora bien, como quiera que el artículo 87.5 del ET se refiere a los sindicatos, federaciones y confederaciones sindicales y no a las «representaciones sindicales», es posible, dada la atomización que deriva de los requisitos de legitimación exigidos en este ámbito y habida cuenta la limitación numérica que impone el artículo $88.3 \mathrm{ET}$, que no todas las secciones sindicales con legitimación negocial tengan cabida en el órgano negociador ${ }^{10}$.

Del lado de los funcionarios, la legitimación negocial puede corresponder también a las secciones sindicales pertenecientes a los sindicatos más representativos y a los que tengan presencia en los órganos de representación unitaria, ya que, aunque la LORAP no contiene mención directa a la legitimación negocial de las secciones sindicales, en

9 Vid. R. ROQUETA BuJ, «Las relaciones...», cit., pp. 141 y ss.; y J. M. LÓPEZ GÓMEZ, El régimen jurídico del personal laboral..., cit., p. 398.

10 Vid. J. Cruz Villalón, «El reconocimiento legal de la representación y acción sindicales en la empresa», en AA.VV., Comentarios a la Ley de Libertad Sindical, Madrid, 1986, p. 256; R. EsCUDERo Rodríguez, Los sujetos de los convenios de empresa, Madrid, 1985, p. 209; la STCO 137/1991, de 20 de junio, y las SSTCT de 20 de junio de 1986 (Ar. 5.337) y de 18 de noviembre de 1987 (Ar. 26.763). Por contra, J. M. ${ }^{a}$ RAmirez MARTíneZ, «Negociación colectiva en la empresa y secciones sindicales», $D L$, n. $^{\circ} 22,1987$, p. 55 , afirma que «si bien el artículo 87.5 no parece directamente aplicable en el supuesto de la negociación de empresa o inferior, el artículo 88.1 viene a suponer su equivalente». 
tanto que dicha legitimación viene referida genéricamente en favor de las organizaciones sindicales, el artículo 8.2.b) de la LOLIS, que es de aplicación en la función pública, les garantiza la legitimación negocial, si se constituyen en un nivel coincidente con el de la Mesa de negociación ${ }^{11}$. La única disfuncionalidad en este punto entre lo dispuesto en la LOLIS y en la LORAP es que no resulta absolutamente concordante la legitimación negocial del artículo 8.2.b) de aquélla y la que se reconoce en el artículo 31.1 de ésta; aunque coincida grosso modo, el segundo precepto resulta algo más restrictivo que el primero ${ }^{12}$. Por ello, al ser menores las exigencias legitimadoras que prescribe la LOLIS puede suceder, que, aunque no exista un tope legal máximo de puestos para la mesa negociadora ${ }^{13}$, la legitimación negocial de las secciones sindicales, que no pertenezcan a un sindicato con el 10 por 100 de representatividad en el ámbito de referencia, no se materialice con su presencia en la mesa negociadora, pues la LOLIS no les garantiza el derecho a ser parte constitutiva de las mesas de negociación; solución, por lo demás, similar a la propugnada por la doctrina y la jurisprudencia en torno a la legitimación negocial de las secciones sindicales de los trabajadores.

\footnotetext{
1 La LORAP ignora a las secciones sindicales como sujeto negocial porque los ámbitos de éstas generalmente son de dimensiones más reducidas que las correspondientes mesas de negociación. Sin embargo, en la esfera local sí puede darse la coincidencia entre los ámbitos de la mesa de negociación y el correspondiente a las secciones sindicales. Por consiguiente, dado que no existe una razón objetiva que justifique la diferencia de tratamiento de las secciones sindicales en los ámbitos laboral y funcionarial, hay que concluir que el artículo 8.2.a) de la LOLIS también garantiza la legitimación negocial de tales secciones sindicales. El hecho de que este artículo les otorgue el derecho a la negociación «en los términos establecidos en su legislación específica» no invalida la tesis propuesta. Pese a que los artículos 30 y 31.2 de la LORAP ignoran a las secciones sindicales, lo cierto es que aquel precepto se proyecta sobre éstos, por lo que es preciso garantizar su legitimación negocial. Además, la lectura al contrario de la discutible literalidad de los artículos 30 y 31.2 de la LORAP encuentra fundamento adicional en la falta de unidad terminológica que se aprecia en esta disposición legal en torno al concepto de "organización sindical», ya que en diversas ocasiones la ley emplea esta expresión para aludir a las secciones sindicales. En parecidos términos se expresan M. F. Fernández LóPez y J. Cruz Villalón, «Los sindicatos en la Función Pública: Régimen jurídico y representaciones sindicales en el centro de trabajo", en AA.VV., Seminario sobre relaciones colectivas en la Función Pública, Sevilla, 1990, p. 235.
}

12 Mientras la LORAP exige al sindicato simplemente representativo que alcance el 10 por 100 de los miembros de la junta de personal o, en su caso, de los delegados de personal, para la LOLIS le basta con la obtención de un representante. Aunque no se trata de una diferencia sustancial, por cuanto que los sindicatos para tener derecho a la atribución de un representante en la junta de personal han de obtener como mínimo el 5 por 100 de los votos en la unidad electoral correspondiente [art. 18.1.b) LORAP], lo cierto es que la LOLIS es más generosa. Subrayan la diferencia M. ${ }^{a} \mathrm{~F}$. FERNÁNDEZ LOPEZ y J. CRUZ VILLALON, «Los sindicatos...», cit., p. 235.

${ }^{13}$ La LORAP, con la concisión, que le caracteriza, no establece el número de puestos de la mesa negociadora ni señala, como hace el ET, un tope máximo. Por lo que, como señala A. OreDA Aviles, «Los derechos de representación y negociación de los funcionarios públicos según la Ley $9 / 1987$, de 12 de mayo», $R L, \mathrm{n}^{\circ} 18,1988, \mathrm{p} .24$, este tema se solventará por consenso entre las partes negociadoras. 
Asi pues, la iegitimación para negociar en representación del personal laboral y funcionarial de las EE.LL. puede corresponder a las secciones sindicales. Además, dado que son posibles las secciones sindicales que integran a todo el personal al servicio de las EE.LL. en una sola organización ${ }^{14}$, estos grupos sindicales podrán actuar en el seno de la mesa negociadora representando al mismo tiempo a ambos colectivos. Pero aun en el supuesto de que los sindicatos que cuenten con legitimación negocial en la unidad de referencia mantengan ramificaciones sindicales diferenciadas para el personal laboral y funcionarial o sólo registren presencia en relación a uno de estos colectivos, no existe obstáculo legal a que se produzca esta combinación de personal laboral y funcionarial dentro de una misma mesa negociadora. En este último caso, del lado social, deberían negociar todas y cada una de las ramificaciones de las organizaciones sindicales representativas en el ámbito laboral y funcionarial.

\subsection{El procedimiento de negociación}

12. En tema de procedimiento negocial, habrá que distinguir, en principio, entre la negociación colectiva laboral y funcionarial. A pesar de que a efectos organizativos internos la mesa de negociación quiera mantener un ámbito de representación que integre a un mismo tiempo a los dos tipos de personal, al desarrollar la actividad negocial, dicha representación deberá cumplimentar los requisitos de forma dispuestos en la legislación correspondiente, que es diversa según se trate de personal laboral o funcionario: en un caso el ET, en otro la LORAP.

13. Las principales diferencias que a este respecto se dan entre la negociación colectiva laboral y funcionarial son las siguientes:

1. ${ }^{\mathrm{a}} \quad$ Mientras los representantes sindicales deben sumar, en su conjunto, la mayoría de los miembros del comité (art. 87.1 ET), en la negociación colectiva funcionarial, en principio, es indiferente la representatividad de conjunto de las representaciones sindicales ${ }^{15}$.

14 M. ${ }^{a}$ F. Fernández López y J. Cruz Villalón, «Los sindicatos...», cit., p. 225.

15 En este sentido, A. Ojeda Avilés, «Los derechos..», cit., p. 21; R. Escudero Rodriguez, «Comentarios a la Ley 9/1987», $D L$, n. $^{\circ} 15,1987$, p. 87; CASAS/BAYLOS/EsCUDERO, «El Estatuto de los Trabajadores. Diez años después de pervivencias, insuficiencias, desviaciones y reformas», $R L, \mathrm{n}{ }^{\circ}$ 6-7, 1990, p. 61. Por contra, C. CARrera OrTIZ, «Naturaleza y eficacia jurídica de la negociación colectiva en la función pública en España», $R E D T, \mathrm{n}^{\circ}{ }^{\circ} 38,1989$, pp. 274 y 275 , entiende que procede la aplicación analógica del ET en este punto. 
2. $\quad$ El acuerdo alcanzado en sede negocial requiere, según dispone el artículo 35 de la LORAP, la aprobación expresa y formal del Pleno de la Entidad Local respectiva; exigencia que no tiene correlación en la letra de los artículos 82 y 90.2 del ET, aplicables incluso cuando el empresario es una entidad pública.

3. $\quad$ La misma diferencia de régimen jurídico se aprecia en el supuesto de que fracase la negociación, ya que mientras en el ámbito laboral la Entidad Local no puede imponer sus condiciones a la representación sindical, entrando en juego las prescripciones contenidas en el artículo 91 del ET y en los Títulos $1 .^{\circ}$ y $2 .^{\circ}$ del RDL $17 / 1977$, de 4 de marzo, sobre relaciones de trabajo (RDLRT) en lo relativo a los conflictos colectivos y. huelgas; en el ámbito funcionarial, en cambio, corresponderá al Pleno de la Entidad Local establecer las condiciones de trabajo aplicables a los funcionarios (art. 37.2 LORAP), salvo que decida someterse a la mediación de un tercero o terceros imparciales (art. 38 LORAP) ${ }^{16}$.

14. Ahora bien, las diferencias de régimen jurídico señaladas no tienen tanta trascendencia como para impedir la negociación conjunta del personal funcionario y laboral.

A este respecto, hay que señalar lo siguiente:

En primer lugar, hay que indicar que la diferencia señalada en cuanto a los requisitos que debe cumplimentar la representación sindical y funcionarial para la válida constitución del banco social no impide la negociación colectiva conjunta de trabajadores y funcionarios. Tales exigencias, según se cumplan o no, proyectarán sus efectos sobre el carácter del acuerdo resultado de la negociación. Mientras la parte correspondiente a los funcionarios tendrá la naturaleza propia del Acuerdó, que estará dotado en todo caso de eficacia jurídica normativa y eficacia personal general; la parte correspondiente a los trabajadores, en cambio, tendrá la naturaleza jurídica de convenio estatutario o extraestatutario, según se cumpla o no con lo dispuesto en el ET.

En segundo lugar, y aunque ciertamente, los artículos 82 y 90.1 del ET son plenamente aplicables cuando el empresario es una entidad pública,

\footnotetext{
${ }^{16}$ La mediación que contempla el artículo 38 es exclusivamente la de carácter voluntario, esto es, aquella en la que se requiere el consentimiento de ambas partes para su iniciación y desarrollo. $\mathrm{Ni}$ siquiera la iniciativa de la parte sindical obliga a la Entidad Local a someterse a la intervención del tercero ajeno al conflicto. De este modo, la ley deja en manos del órgano de Gobierno local la regulación unilateral de la materia o la apertura de una segunda fase de negociación con la mediación de un tercero imparcial. Vid. A. OJEDA AvILÉs, «Los derechos...», cit., p. 26.
} 
el acuerdo resultado de la negociación colectiva laboral también requiere la aprobación del Pleno de la Entidad Local, ya que, como hemos visto, de acuerdo con los artículos 22 y 33 de la LBRL, le corresponde aprobar la plantilla de personal, la relación de puestos de trabajo y los presupuestos; aspectos todos ellos de gran trascendencia y que repercuten sobre la práctica totalidad de las condiciones de trabajo.

Finalmente, la diferencia de régimen jurídico señalada en tercer lugar se materializará cuando se produzca un desacuerdo en la negociación colectiva, pero no cuando, como en el supuesto que aquí se comenta, existe pleno acuerdo entre las partes.

\subsection{El contenido de la negociación}

15. Existen profundas diferencias en cuanto al ámbito objetivo y límites de la autonomía colectiva entre los sistemas de negociación colectiva laboral y funcionarial; entre ellas cabe destacar las siguientes:

En primer lugar, la enumeración de las materias incluidas y vedadas a la negociación colectiva funcionarial contenidas respectivamente en los artículos 32 y 34 de la LORAP, no sólo hacen sustancialmente más restrictiva su regulación que la resultante de los artículos 82 y 85 del ET para los trabajadores, sino que tiene, también, el referente insoslayable de que los acuerdos versarán sobre materias competencia del Consejo de Ministros, Consejos de Gobierno de las CC.AA. o Pleno de las EE.LL. (art. 35 LORAP) ${ }^{17}$. Así, aunque el artículo 32.k) de la LORAP, a diferencia del artículo $85 \mathrm{ET}$, no hace mención expresa al necesario respeto de las leyes por los Pactos y Acuerdos, es evidente que éste sigue siendo un límite de la autonomía colectiva ${ }^{18}$. La posición claramente subordinada que los instrumentos negociales ocupan en el ordenamiento jurídico comporta respecto a la Ley restricciones en la esfera de la actividad negocial. En este sentido, debe significarse que las reglas que van a determinar esa relación entre los acuerdos negociales y la ley es una transposición de las que rigen la relación ley y reglamento. Lo cual significa, en primer lugar, que la negociación colectiva no podrá abordar aquellos aspectos que están ya predeterminados por la ley o sobre los que recae reserva de ley. Así, la inclusión de una materia en el

\footnotetext{
17 STS de 22 de octubre de 1993 (Ar. 7.544), f.j. n. ${ }^{\circ} 7$.

${ }^{18}$ Así lo subraya, aunque en relación con los Pactos y Acuerdos aplicables al personal estatutario, la STS de 14 de febrero de 1992 (Ar. 988).
} 
ámbito de la negociación propiamente dicha no quiere decir que ésta pueda abordar todas y cada una de las cuestiones, sino tan sólo aquellas que entren dentro del ámbito de disponibilidad de la Administración correspondiente. Y, en segundo lugar, y mientras en el ámbito laboral el principio de jerarquía normativa viene matizado por el de norma mínima, aquí no admite matizaciones ${ }^{19}$.

En segundo lugar, teniendo en cuenta que el Estado tiene competencia exclusiva para fijar las bases del régimen estatutario de los funcionarios y que a las CC.AA. con competencias normativas en materia de función pública local les corresponde el desarrollo de las bases estatales, las EE.LL. están subordinadas al poder normativo del Estado y de las CC.AA. De este modo, el poder normativo de las EE.LL. es residual en la medida en que sólo puede jugar allí donde no hayan llegado poderes normativos superiores ${ }^{20}$.

16. Sin embargo, las diferencias en este tema entre la negociación colectiva del personal laboral y funcionarial al servicio de la Administración Pública no son tan grandes, y ello por una triple razón ${ }^{21}$ : en primer lugar, porque existe un acercamiento entre el Derecho funcionarial y el laboral, en lo que respecta a la regulación de las «relaciones individuales»; en segundo lugar, porque la Ley 30/1984, de 2 de agosto, de Medidas para la Reforma de la Función Pública (LMRFP) y otras normas administrativas, aun manteniendo la dualidad de regímenes normativos en el seno de la Administración -el laboral y el funcionarial-, otorgan, no obstante, un tratamiento jurídico paralelo e,

\footnotetext{
19 Asi lo subrayan, aunque en relación con el personal estatutario, entre otras, las SSTS de 19 de abril, 22 de septiembre y 28 de octubre de 1991 (Ar. 6.238, 6.474 y 7.749 ) y 4 y 17 de marzo de 1992 (Ar. 1.615 y 1.660), 16 de noviembre de 1994 (Ar. 555), 30 de octubre, 7 de noviembre y 4 de diciembre de 1995 (Ar. 7.907, 8.173 y 1.564), 18 de noviembre de 1996 (Ar. 9.749), 10 de febrero, 30 de junio y 5 de diciembre de 1997 (Ar. 1.409, 6.138 y 9.327), 21 de noviembre y 5 de diciembre de 1997 (Ar. 306 y 307, 1998), y 20 de enero de 1998 (Ar. 1.419).

${ }^{20}$ En este sentido, la STS de 22 de octubre de 1993 señala lo siguiente: «El marco de contractualidad, por tanto, está en correlación con el contenido de las potestades normativas y de autoorganización del órgano administrativo correspondiente y, por otra parte, las caracteristicas de pormenorización, rigidez y uniformidad inherentes al régimen estatutario emanado de la legislación básica del Estado y, en su caso, de los órganos legislativos de las Comunidades Autónomas, no permiten que por analogía con el sistema de relaciones laborales $\{.$.$\} , tal bloque legislativo sea identificable$ como plataforma de "mínimos", sobre la que pueda pivotar una constelación de unidades negociadoras pactando cada una a su libre albedrío, bajo el lema de que lo que no está prohibido por la ley debe presumirse que está permitido y puede ser objeto de regulación con arreglo al buen criterio de la Mesa de Negociación, refrendado por la respectiva Corporación Municipal.»
}

${ }^{21}$ Vid. con mayor detalle R. RoQUETA BuJ, «Las relaciones...», cit., pp. 142 y ss.; J. M. LOPEZ GÓMEZ, El régimen juridico..., cit., pp. 402 y ss.; y P. FernÁNDEZ ArTIACH, «Política de rentas en el sector público», $T S$, n. $^{\circ} 78,1997$, pp. 48 y ss. 
incluso, unitario en ciertos aspectos de las relaciones jurídicas de los empleados públicos; en tercer lugar, porque la negociación colectiva del personal laboral al servicio de la Administración Pública, al igual que la negociación del personal funcionario, está sometida en materia salarial y de Seguridad Social complementaria a los dictados de las normas presupuestarias.

Como consecuencia de todo lo anterior, el bloque de Derecho necesario que han de respetar los sistemas de negociación colectiva laboral y funcionarial en la regulación de estas materias viene a tener idénticos contornos. Por ello, la negociación de estas materias no requiere la separación entre personal laboral y funcionarial. Antes al contrario, sería aconsejable la consideración conjunta de ambos colectivos en aras de la consecución de los principios de igualdad, economía normativa y eficacia administrativa.

Por lo demás, y en relación con el resto de materias, aunque el ámbito y los límites de la negociación colectiva funcionarial son sustancialmente más restrictivos que los de la negociación colectiva laboral, nada impide que esta última actúe dentro del marco de la primera. $\mathrm{E}$, incluso, cabe un pacto que abarque conjuntamente al personal laboral y a los funcionarios que ofrezca, no obstante, un tratamiento diferenciado a los mismos en aspectos concretos.

\subsection{La jurisdicción competente}

17. La distinta jurisdicción a que se debe acudir para impugnar los convenios colectivos y los Acuerdos que resultan de la negociación conjunta del personal laboral y funcionario, y para dirimir los contenciosos que plantea su aplicación, según sean contratados laboralmente o funcionarios, es otra de las diferencias jurídico-positivas que distingue a ambos sistemas de negociación insoslayable ${ }^{22}$. En realidad, se puede decir, a la

\footnotetext{
${ }^{22}$ Las disposiciones normativas que pueden servir de presupuestos normativos donde encuadrar el problema de la jurisdicción competente son los artículos 1 y 3 de la Ley 29/1998, de 13 de julio, Reguladora de la Jurisdicción Contencioso-Administrativa (LRJCA) y los artículos 2 y 3 del Real Decreto Legislativo $2 / 1995$, de 7 de abril, por el que se aprueba el Texto Refundido de la Ley de Procedimiento Laboral (LPL). Realizando una interpretación de conjunto, hay que distinguir los siguientes supuestos:
}

a) Los tribunales del Orden Contencioso-Administrativo son competentes para resolver los conflictos individuales y colectivos que plantea la aplicación del Acuerdo Local Mixto en relación con los funcionarios, por cuanto los artículos 1.1 y 3 de la LRJCA y LPL, respectivamente, asignan a 
vista de lo expuesto en las páginas precedentes, que la diferencia de jurisdicción es lo que separa a los dos sistemas de negociación que conviven en el seno de la Administración Pública ${ }^{23}$.

Sin embargo, esta dualidad jurisdiccional no impide la negociación conjunta del personal laboral y funcionario. Nótese que esta anómala situación también se da en relación con los Pactos y Acuerdos del sector sanitario, ya que la competencia para resolver los conflictos individuales y colectivos que se planteen en relación con el contenido normativo individual de los mismos corresponde a los órganos del Orden Social o del Contencioso-Administrativo, según afecten a los funcionarios sanitarios de las AA.PP. o a los funcionarios sanitarios de la Administración de la Seguridad Social y personal estatutario, respectivamente.

18. A la vista de lo expuesto, se concluye que, a diferencia de lo que sostiene el Tribunal Supremo, los ordenamientos jurídicos de la negociación colectiva laboral y funcionarial ofrecen entre sí el grado de permeabilidad suficiente para posibilitar una negociación unitaria.

\section{LA IMPUGNACIÓN DE LOS ACUERDOS LOCALES MIXTOS}

19. Los Acuerdos Locales Mixtos, como el que se analiza en la Sentencia objeto de comentario, una vez han sido aprobados por el Pleno de

este orden el conocimiento de las pretensiones deducidas de los actos de la Administración sometidos a Derecho administrativo.

b) Los tribunales del Orden Social de la Jurisdicción son competentes para resolver los conflictos individuales y colectivos que plantea la aplicación del Acuerdo Local Mixto en relación con los trabajadores, pues el artículo 2 de la LPL en relación con el artículo 3.a) de la LRJCA asignan a este orden los litigios entre empresarios y trabajadores como consecuencia del contrato de trabajo.

Por su parte, A. Ojeda Avilés, Compendio de Derecho Sindical, Madrid, 1998, p. 403, entiende que la jurisdicción competente para resolver los conflictos que se planteen en torno a estos instrumentos negociales unitarios respecto de las relaciones individuales y colectivas (libertad sindical y derecho de huelga) es distinta, según se trate de trabajadores o funcionarios: en un caso la social, en otro la contencioso-administrativa.

Sobre la competencia para resolver la impugnación y para interpretar los instrumentos negociales unitarios se vuelve en el apartado siguiente, a cuyo momento se remite el análisis.

${ }^{23}$ En este sentido, se ha afirmado por la doctrina iuslaboralista que hoy puede decirse que la diferencia de jurisdicción es lo único que separa a la función pública de un tratamiento homogéneo con los trabajadores comunes. Así, M. PÉREZ PÉREZ, «Derecho del trabajo y nuevos sistemas tecnológi$\cos », R L$, n. ${ }^{\circ} 20,1988$, p. 25. 
la Entidad Local y cumplimentados los trámites de formalización externa correspondientes, poseerán una naturaleza jurídica dual ${ }^{24}$ :

a) La parte correspondiente a los primeros tendrá la naturaleza jurídica de convenio colectivo estatutario o extraestatutario según cumpla o no las exigencias legales. Así, si cumple los requisitos de legitimación y forma que el Título III del ET establece, tendrá la naturaleza propia de los convenios colectivos estatutarios, esto es, tendrá eficacia jurídica normativa y eficacia personal general. De no ser este el caso, se tratará de un convenio colectivo extraestatutario, de eficacia personal limitada a los trabajadores representados por los sindicatos firmantes y con una eficacia jurídica normativa o contractual según se acepte una u otra para los resultados de la negociación colectiva extraestatutaria, tema discutido doctrinal y jurisprudencialmente.

b) La parte correspondiente a las condiciones de trabajo de los funcionarios tendrá la naturaleza propia del Acuerdo ${ }^{25}$, esto es, un «contrato colectivo reglamento» o un "reglamento reforzado» dotado en todo caso de eficacia jurídica normativa y de eficacia personal general ${ }^{26}$.

\footnotetext{
${ }^{24}$ Sobre la naturaleza del Acuerdo para modernizar la Administración y Mejorar las condiciones de trabajo de los Empleados Públicos de 16 de noviembre de 1991 (AMA), que es un Acuerdo mixto, ver R. EsCUdero Rodríguez, «El Acuerdo para la modernización de la Administración Pública. La Orden de cotización para 1992 y otras normas laborales», RL, I/1992, pp. 1132 y ss.; A. OJEDA AvILÉs, «El "Acuerdo para modernizar la Administración y mejorar las condiciones de trabajo": un importante avance en la negociación colectiva pública», $A L, \mathrm{n} .{ }^{\circ} 17,1992$, pp. 325 y ss.; R. RoQUETA BuJ, «El proceso de formación y remodelación de la estructura de la negociación colectiva laboral en el ámbito de la Administración del Estado", $R T$, n. ${ }^{\circ} 11,1993$; J. M. LóPEZ GómEz, El régimen jurídico..., cit., pp. 427 y ss.; y J. RIVERo LAMAS, «El proceso de laboralización de la función pública: aspectos críticos y límites», Revista Aragonesa de Administración Pública, n. $^{\circ} 6-7,1995$, pp. 117 y ss. Sin embargo, hay que advertir que las conclusiones que se extraen de estos trabajos no son extrapolables al supuesto aquí comentado, por cuanto la función del AMA no es propiamente la de establecer condiciones de trabajo del personal laboral y funcionarial, sino la de delimitar las unidades de negociación y la articulación funcional entre las mismas.
}

${ }^{25}$ Hay que subrayar que en el ámbito de las EE.LL. no cabe la figura del Pacto a que se refiere el artículo 35 de la LORAP, ya que la titularidad del poder reglamentario corresponde, en exclusiva, al Pleno.

${ }^{26}$ Los Acuerdos constituyen un "contrato colectivo reglamento» o un «reglamento reforzado", ya que es el acto de aprobación el que, al asumir el contenido del Acuerdo, le que confiere la fuerza normativa. En esta posición se sitúan, entre otros, A. BLASCo ESTEVE, «La negociación colectiva de los funcionarios públicos en la Administración Local», cit., pp. 2171-2172; M. ${ }^{a}$ E. CASAS BAAMONDE, «Los derechos sindicales de los funcionarios públicos en las Administraciones Públicas Vascas», en AA.VV., Administración Pública y Sindicalismo, Zarautz, 1988, p. 96; J. LóPEZ GANDIA, «La negociación colectiva de los funcionarios públicos», Revista de Treball, $\mathrm{n}{ }^{\circ} 8,1988$, p. 24; V. A. MARTINEZ ABASCAL, «Contenido de la negociación colectiva: materias de consulta obligatoria y de consulta potestativa", en AA.VV., Seminario sobre relaciones colectivas en la Función Pública, Sevilla, 1990, p. 316; T. Sala Franco, «Administraciones públicas y derechos sindicales», en AA.VV., Administración y Sindicalismo, Zarautz, 1988, p. 68. 
Por consiguiente, y por lo que se refiere a la impugnación debe distinguirse ${ }^{27}$ :

- La impugnación del Acuerdo Local Mixto en cuanto convenio colectivo debe residenciarse ante los tribunales del Orden Social de la Jurisdicción como cualquier convenio colectivo.

- La impugnación del Acuerdo Local Mixto en cuanto Acuerdo debe residenciarse ante los tribunales del Orden Contencioso-Administrativo de la Jurisdicción 28 .

Tales tribunales son independientes entre sí, por lo que los fallos pueden ser contradictorios, sin que la nulidad del Acuerdo Local Mixto en cuanto Acuerdo comporte su nulidad en cuanto convenio colectivo y viceversa.

20. Los problemas surgen cuando, como en el supuesto de autos, el conflicto jurídico se suscita, no en relación con el Acuerdo Local Mixto, ya sea en cuanto convenio o en cuanto Acuerdo, sino en relación con el acuerdo del Pleno de la Entidad Local que lo aprueba. En principio, hay

Por su parte, A. OjeDA Avılés, "Validez y eficacia de la negociación colectiva funcionarial», en AA.VV., Seminario sobre relaciones colectivas en la Función Pública, Sevilla, 1990, p. 291, considera que los Acuerdos revisten la naturaleza jurídica de los «contratos administrativos especiales». Sin embargo, con posterioridad matiza esta opinión, al afirmar que los Acuerdos «tienen naturaleza contractual - aunque estén fuera de la LCE o normas análogas»; contratos a los que reconoce «carácter normativo». Vid. Derecho..., cit., pp. 776 y 777.

Finalmente, C. Carrera Ortiz, «Naturaleza..», cit., pp. 270 y ss., y S. Del Rey Guanter, Comentarios a la Ley de Órganos..., cit., pp. 234 y ss., ven en el acto de aprobación un acto administrativo similar al acto de aprobación de los convenios colectivos del sistema de negociación colectiva laboral precedente, mediante el cual el órgano gubernamental efectúa un control de legalidad y oportunidad sobre el Acuerdo concluido en sede negocial, el cual, tras superar dicho control, despliega una eficacia jurídica normativa directa.

27 Por contra, A. OJEDA Avilés, Compendio de Derecho..., cit., p. 403, a partir de una interpretación estricta y restrictiva de los términos «libertad sindical» y «derecho de huelga» del artículo 3.a) de la LPL y teniendo en cuenta la naturaleza sindical de los instrumentos negociales que nos ocupan y el tratamiento conjunto de trabajadores y funcionarios en la LOLIS, concluye que la impugnación e interpretación de estos instrumentos negociales unitarios corresponden en exclusiva a la jurisdicción social por los trámites del proceso de conflicto colectivo. Sin embargo, aunque, ciertamente, el artículo 3.a) de la LPL no menciona expresamente el derecho de negociación colectiva funcionarial, el hecho de que se trate de un derecho "sindicalizado» hace evidente su inclusión en la excepción del citado artículo.

${ }^{28}$ Las funciones de control de la legalidad de los Pactos y Acuerdos están confiadas al orden jurisdiccional contencioso-administrativo. Así lo subrayan, aunque en relación a los que regulan las condiciones de trabajo del personal estatutario, la STS de 1 de diciembre de 1992 (Ar. 9.881), y las SSTSJ de Castilla y León de 4, 11 y 25 de septiembre, y de 5 de octubre de 1989 (Ar. 1.936, 1.943, 1.960 y 1.985$)$. 
que señaiar que éste posee una naturaleza jurídica distinta según afecte a unos u a otros. Con respecto a los trabajadores, constituye un simple acto administrativo sin otra finalidad que la de perfeccionar la voluntad negocial de la Entidad Local, de forma que el convenio conserva en plenitud su naturaleza convencional. Con respecto a los funcionarios, constituye, en cambio, un verdadero y auténtico reglamento, esto es, un acto creador de normas generales y abstractas, que despoja al Acuerdo de su originario carácter negociado y lo convierte en reglamentación local.

Establecido el carácter de acto administrativo y de reglamento del acuerdo plenario, es evidente, a la luz de lo dispuesto en el artículo 1 de la Ley 29/1998, de 13 de julio, Reguladora de la Jurisdicción Contencioso-Administrativa (LRJCA), que su impugnación debe realizarse en todo caso ante los tribunales de la jurisdicción contencioso-administrativa.

Éstos deberán proceder a efectuar sucesivamente las siguientes operaciones:

En primer lugar, deberán verificar si en la negociación del Acuerdo Local Mixto aprobado por el Pleno se han observado o no los límites formales que acantonan el lícito ejercicio de la actividad negocial de trabajadores y funcionarios. Para enjuiciar correctamente el fenómeno hay que subrayar que, a diferencia de lo que sostiene el Tribunal Supremo, no procede la declaración de nulidad del acuerdo plenario por el que se aprueba el Acuerdo Local Mixto, por el mero hecho de que éste regule unitariamente las condiciones de trabajo de los trabajadores y funcionarios, pues, como se ha visto, los sistemas de negociación colectiva laboral y funcionarial ofrecen entre sí el grado de permeabilidad suficiente para posibilitar la negociación unitaria de ambos colectivos. Además, aunque la refundición en un solo documento de los dos actos por los que el Pleno aprueba el convenio y el Acuerdo, siendo que su naturaleza jurídica es diferente, vulnera el contenido del artículo 55.3 de la Ley 30/1992, de 26 de noviembre, de Régimen Jurídico de las Administraciones Públicas y del Procedimiento Administrativo Común (LRJPA) ${ }^{29}$, debe subrayarse que

29 Según el citado artículo, «cuando deba dictarse una serie de actos administrativos de la misma naturaleza, tales como nombramientos, concesiones o licencias, podrán refundirse en un único acto, acordado por el órgano competente, que especificará las personas u otras circunstancias que individualicen los efectos del acto para cada interesador. Este artículo recoge -con pequeñas modificaciones- el contenido del artículo 42 de la Ley de Procedimiento Administrativo de 17 de julio de 1958 (LPA), que es la que estaba vigente en el momento en que ocurren los hechos enjuiciados por la Sentencia objeto de comentario. Sobre la refundición en un solo documento de varios actos ver, por todos, J. González Pérez y F. González Navarro, Régimen Juridico de las Administraciones Públicas y Procedimiento Administrativo Común (Ley 30/1992, de 26 de noviembre), Madrid, 1994, p. 748. 
se trata de una irregularidad no invalidante, pues ni implica prescindir totalmente del procedimiento legalmente establecido ni tampoco el acuerdo aprobatorio carece de los requisitos para alcanzar su fin y no da lugar a la indefensión de los interesados (art. 63.2 LRJPA).

Así pues, ninguna de estas circunstancias exonera a los Tribunales de su obligación de examinar si en la negociación del Acuerdo Local Mixto se ha observado el procedimiento legalmente establecido para la negociación colectiva laboral y funcionarial. $\mathrm{Si}$, como consecuencia de dicho análisis, se aprecia la existencia de un defecto de índole formal grave, como, por ejemplo, cuando no se hayan observado las normas que determinan la competencia o la legitimación negocial, deberán declarar, de conformidad con los apartados 1 y 2 del artículo 62 de la LRJPA, la nulidad del acuerdo plenario. La ilegalidad de forma, esto es, la infracción de los requisitos subjetivos o formales exigidos para la negociación del Acuerdo Local Mixto en cuanto convenio colectivo y, sobre todo, en cuanto Acuerdo vicia de por sí al acuerdo plenario como un todo.

En segundo lugar, y de haberse observado las exigencias anteriores, los tribunales deberán abordar el análisis y enjuiciamiento de los fundamentos de las pretensiones de las partes acerca de los límites materiales de la negociación colectiva ${ }^{30}$. Es más, aun cuando procediera la nulidad del acuerdo plenario por motivos formales, ello no les releva, como sostiene el Tribunal Supremo ${ }^{31}$, de su obligación de abordar el análisis y enjuiciamiento de las pretensiones de las partes acerca del contenido del Acuerdo Local Mixto; pues dicha actitud constituye una desafortunada interpretación del carácter revisor del orden judicial contencioso-administrativo 32 :

Así pues, por razones de obligada congruencia con las pretensiones mantenidas en el proceso, deben efectuarse las siguientes consideraciones sobres las estipulaciones del Acuerdo que fueron impugnadas.

\footnotetext{
${ }^{30}$ Ver, en este sentido, entre otras, las SSTS de 4 de diciembre de 1995 (Ar. 1.564) y 14 de octubre de $1996\left(A L\right.$ n. $\left.^{\circ} 6 / 1997\right)$.

${ }^{31}$ El citado tribunal, tras declarar la nulidad de las estipulaciones del Acuerdo Local Mixto sobre la base de que es inviable la negociación conjunta de funcionarios y trabajadores, señala que dicha anulación «nos releva de abordar el análisis y enjuiciamiento de los fundamentos de la Sentencia, ya sean referidos a los motivos de nulidad invocados por la Administración demandante o las alegaciones de contrario, sostenidas por el Ayuntamiento demandado» (STS de 22 de octubre de 1993, f.j. 7).

32 Ver S. MuÑoz Machado, «Nuevos planteamientos sobre el carácter revisor de la jurisdicción contencioso-administrativa", REDA, n. ${ }^{\circ} 26,1980$, pp. 496 y ss.; y T. R. FernÁNDEZ Rodríguez, La doctrina de los vicios de orden público, Madrid, 1969, pp. 154 y ss.
} 
Sobre el particular habría que decir lo siguiente:

a) El artículo 6 infringía lo dispuesto en el artículo 30.1.f) de la LMRFP, en relación con el artículo 94 de la LBRL ${ }^{33}$, ya que el primero sólo reconoce la reducción de jornada a los funcionarios con hijos menores de 6 años ${ }^{34}$.

b) El artículo 7 vulneraba lo dispuesto en el artículo 68 del Decreto $315 / 1964$, de 7 de febrero, por el que se aprueba el Texto Articulado de la Ley de Funcionarios Civiles del Estado (LFCE), de acuerdo con el cual «todos los funcionarios tendrán derecho a disfrutar, durante cada año completo de servicio activo, de una vacación retribuida de un mes, o a los dias que en proporción le correspondan si el tiempo servido fue menor» ${ }^{35}$.

c) El artículo 9 estaba en pugna con el apartado séptimo de la Instrucción de la Secretaría del Estado para la Administración Pública de 21 de diciembre de 1983, redactado conforme a la Resolución de la Secretaría de Estado de 27 de agosto de 1985, aplicable con carácter supletorio a los funcionarios de las EE.LL. ubicadas en la Comunidad Autónoma de Castilla-La Mancha, dado el silencio que a este respecto mantenía la legislación autonómica (art. 142 TRRL), de acuerdo con el cual los funcionarios sólo tenían derecho a disfrutar de 6 días por este concepto.

${ }^{33}$ El articulo 94 de la LBRL dice que «la jornada de trabajo de los funcionarios de la Administración Local será en cómputo anual la misma que se fije para los funcionarios de la Administración Civil del Estado» y que «se les aplicarán las mismas normas sobre equivalencia y reducción de jornada»!

$3^{34}$ : STS de 14 de octubre de $1996\left(A L\right.$ n. ${ }^{\circ}$ 6/1997).

${ }^{35}$ De acuerdo con el artículo 142 del Real Decreto Legislativo 781/1986, de 18 de abril, por el que se aprueba el Texto Refundido de las disposiciones legales vigentes en materia de Régimen Local (TRRL), «los funcionarios de la Administración Local tendrán derecho a las recompensas, permisos, licencias y vacaciones retribuidas previstas en la legislación sobre función pública de la Comunidad Autónoma respectiva y, supletoriamente, en la aplicable a los funcionarios de la Administración del Estadom. Por consiguiente, las EE.LL. carecen de competencia para pactar el régimen jurídico aplicable a tales extremos (SSTS de 16 de noviembre de 1994 [Ar. 555], 16 de junio de 1995 [AL n. ${ }^{\circ}$ 1/1996], 30 de octubre de 1995 [Ar. 7.907], 4 de diciembre de 1995 [Ar. 1.564], 14 de octubre de 1996 [ $A L$ n..$^{\circ}$ /1997], 3 de febrero de 1997 [Ar. 923], 10 de febrero de 1997 [Ar. 1.409], 30 de junio de 1997 [Ar. 6.138] y 5 de noviembre de 1997 [Ar. 306, 1998]). Pues bien, como quiera que la legislación funcionarial de la Comunidad Autónoma de Castilla-La Mancha vigente el 22 de marzo de 1989, fecha en la que se aprueba por el Ayuntamiento de Albacete el convenio sobre personal, no dice nada a este respecto, debe estarse a lo dispuesto en la regulación contenida en la legislación estatal. 
d) Se producía también la vulneración del artículo 25 de la Ley $37 / 1988$, al establecer un incremento global de las remuneraciones en cuantía superior al 4 por 100 que fijaba aquel precepto ${ }^{36}$.

e) El derecho a percepción de pagas extraordinarias durante el tiempo de cumplimiento del servicio militar o servicio civil sustitutorio (art. 30) infringía el artículo 29.2 de la LMRFP, que, con el carácter de norma básica, establece que los funcionarios en situación de servicios especiales «recibirán las retribuciones del puesto o cargo efectivo que desempeñen y no las que les correspondan como funcionarios, sin perjuicio del derecho a la percepción de los trienios que pudieran tener reconocidos como funcionarios».

f) La ruptura del concepto unitario del complemento de productividad, escindiéndolo en tres, vulneraba los artículos 23 de la LMRFP y 93 de la LBRL, que, con el carácter de básicos, disponen que las retribuciones básicas y complementarias de los funcionarios locales tendrán la misma estructura que las establecidas con carácter general para toda la función pública, de forma que las mesas negociadoras locales no pueden crear otros conceptos retributivos no previstos en la LMRFP ni alterar los rasgos que presentan los previstos en esta Ley ${ }^{37}$.

g) La incentivación mediante el abono de cantidades a tanto alzado a quienes optasen por la jubilación anticipada, vulneraba la Disposición Final 2. de la LBRL, a cuyo tenor los funcionarios públicos locales tendrán la protección social que se dispense a los funcionarios públicos de la Administración del Estado ${ }^{38}$.

\footnotetext{
${ }^{36}$ Hay que tener en cuenta que el Tribunal Constitucional ha dicho que «no resulta injustificado que, en razón de una política de contención de la inflación a través de la reducción del déficit público, y de la prioridad de las inversiones públicas frente a los gastos consuntivos, se establezcan por el Estado topes máximos globales al incremento de la masa retributiva de los empleados públicos» (STCO 63/1986, de 21 de mayo). Es más, el citado Tribunal ha venido a reconocer que esta actuación estatal encuentra su apoyo no sólo en la competencia estatal de dirección de la actividad económica general (ex art. 149.1.13), como medida «dirigida a contener la expansión del gasto público», sino que «la competencia estatal invocada, en primer lugar (ex. art. 149.1.18 CE), para regular las bases del régimen estatutario de los funcionarios, puede extenderse a incluir en ella "previsiones relativas a las retribuciones de los funcionarios, comunes a todas las Administraciones, lo que, a su vez, hallaria fundamento en los principios constitucionales de igualdad y solidaridad" (STCO 96/1990, de 24 de mayo). Ver a este respecto, entre otras, la STS de 30 de junio de 1997 (Ar. 6.138) y la STSJ del País Vasco de 29 de noviembre de $1996\left(A A\right.$ n. $\left.^{\circ} 3 / 1997\right)$.

${ }^{37}$ SSTS de 23 de julio de 1996 (Ar. 5.743), 22 de febrero y 30 de junio de 1997 (Ar. 1.497 y 6.138).

${ }^{38}$ STS de 4 de diciembre de 1995 (Ar. 1.564).
} 
Finalmente, hay que señalar que la ilegalidad material tanto por infracción genérica como de las reglas de distribución de competencias entre las AA.PP. en materia funcionarial puede afectar al acuerdo plenario como un todo o, como en el supuesto analizado, sólo a la parte correspondiente al personal funcionario o laboral, en cuyo caso se plantea el problema de determinar si la declaración de su nulidad en cuanto Acuerdo comporta su nulidad en cuanto convenio colectivo y viceversa ${ }^{39}$. En principio, el Acuerdo Local Mixto podría ser contemplado como una pluralidad negocial sometida a diferentes regímenes jurídicos, de forma que la nulidad del acuerdo plenario respecto de los funcionarios no tendría por qué arrastrar el mismo efecto hacia el ámbito laboral y viceversa. Sin embargo, habrá que preguntarse si la voluntad de la Entidad Local y de los representantes sindicales ha sido la de dar un tratamiento unitario a las relaciones de trabajo de funcionarios y laborales. Si éstos han querido dar una interdependencia interna al contenido del todo el Acuerdo Local Mixto, el juez deberá disponer la entera nulidad del acuerdo plenario [arts. 64.2 y LRJPA y 71.1.a) LRJCA] ${ }^{40}$.

21. A la vista de lo expuesto y como conclusión, se puede decir que no existen obstáculos a que trabajadores y funcionarios de las EE.LL. negocien conjuntamente sus condiciones de trabajo y a que los instrumentos negociales que resulten se materialicen en un único documento. Sin embargo, como quiera que es posible la impugnación del acuerdo del Pleno por el que se aprueba dicho Acuerdo ante los tribunales del Orden de la Jurisdicción Contencioso-Administrativa, la falta de tradición tutelar de la misma con relación a los derechos colectivos de los funcionarios conduce a fallos como el de la Sentencia objeto de comentario. Por ello, y

\footnotetext{
${ }^{39}$ A este respecto, conviene notar que las STS que declaraban la nulidad de lo acuerdos plenarios en los que se aprobaban convenios aplicables a funcionarios y trabajadores porque los primeros carecían del derecho a la negociación colectiva, rechazaban la posibilidad de invalidación limitada a la parte correspondiente al personal funcionario, por cuanto ello implicaría destruir la inescindible unidad de contenido del acuerdo aprobatorio adoptado por la Entidad Local. Véanse, en este sentido, las SSTS de 1 de marzo de 1983 (Ar. 1.357), 22 de octubre de 1986 (Ar. 8.048), 27 de enero de 1987 (Ar. 2.002), y las SSTS de 29 de junio y 30 de octubre de 1992 (Ar. 5.195 y 8.397), 17 y 22 de marzo de 1993 (Ar. 2.073 y 2.116 ).
}

La STCT de 24 de febrero de 1986 (Ar. 1.156) mantiene una postura distinta al respecto, al afirmar que «del contexto de esta Sentencia se deduce claramente que la nulidad del acuerdo del Ayuntamiento es declarada en cuanto aprueba las condiciones de trabajo de los funcionarios, sin que se aprecie causa alguna, ni de forma ni de fondo, que autorice la extensión de dicha nulidad a la misma regulación paccionada de las relaciones de naturaleza laboral» y que la «nulidad del acuerdo respecto de los funcionarios no arrastra el mismo efecto hacia el ámbito laboral».

40 Sobre el principio utile per inutile non vitiatur ver, por todas, la STS de 23 de junio de 1992 (Ar. 5.312) referida a un supuesto de hecho diferente al aquí contemplado, pero con el que mantiene una cierta semejanza. 
como medida de precaución, lo más aconsejable es que, sin perjuicio de que se siga negociando conjuntamente las condiciones de trabajo de ambos colectivos, dicha negociación se materialice en instrumentos negociales distintos y formalmente separados según alcancen al personal laboral o funcionario, esto es, en convenios colectivos y en Acuerdos, respectivamente. Y, si se quiere dar un tratamiento igualitario a las relaciones de trabajo laborales y funcionariales, dicho igualitarismo puede obtenerse por la vía de incluir en cada uno de ellos una cláusula en la que se vincule la suerte de ambos, de forma que la nulidad global o parcial de uno de ellos declarada por la jurisdicción correspondiente determine la necesidad de renegociar el acuerdo o la cláusula en cuestión en relación a todo el personal tanto laboral como funcionarial. 